\title{
The Taste of Waste: The Edge of Eggshell Over Calcium Carbonate in Acrylonitrile Butadiene Rubber
}

\author{
Eshwaran Subramani Bhagavatheswaran ${ }^{1,2} \cdot$ Amit Das $^{1} \cdot$ Hadi Rastin $^{3} \cdot$ Hoda Saeidi $^{3,4} \cdot$ Seyed Hassan Jafari ${ }^{3}$. \\ Henri Vahabi ${ }^{5,6} \cdot$ Farhood Najafi $^{7} \cdot$ Hossein Ali Khonakdar $^{1,8} \cdot$ Krzysztof Formela $^{9}$ (D) Maryam Jouyandeh ${ }^{4,10}$. \\ Payam Zarrintaj ${ }^{4,11,12} \cdot$ Mohammad Reza Saeb ${ }^{4,7}$
}

Published online: 17 August 2019

(c) The Author(s) 2019

\begin{abstract}
Rubber technology experiences a new age by the use of biowaste or natural fillers. In this regard, taking properties of reinforcing agents from biowaste fillers remains as the challenging matter. Chicken eggshell (ES) biowaste has recently been introduced to substitute calcium carbonate $\left(\mathrm{CaCO}_{3}\right)$ duo to its superior properties and low price. In this work, composites based on acrylonitrile butadiene rubber (NBR) reinforced with ES and $\mathrm{CaCO}_{3}$ microfillers at various loading levels were prepared and characterized. To improve the interactions between fillers and the NBR matrix, ES and $\mathrm{CaCO}_{3}$ were surfacefunctionalized using a terpolymer, namely poly(vinyl 2-pyrrolidone-co-maleic acid-co-acrylic acid). Fourier-transform infrared spectroscopy (FTIR) and thermogravimetric analysis (TGA) were used to characterize the modified fillers. The incorporation of the functionalized fillers resulted in a significant rise in the maximum torque according to the rheometric measurements. The Young's modulus of the ES-based and $\mathrm{CaCO}_{3}$-based compounds showed a mild improvement over a wide range of filler contents. The elongation at break of the NBR composites, however, was dependent on the filler content. This work provides exciting opportunities for the design of novel and innovative coupling agents to be used in rubber applications.
\end{abstract}

Keywords Eggshell biowaste $\cdot$ Surface functionalization $\cdot$ Polymer composite $\cdot$ Rubber technology

Hossein Ali Khonakdar

h.khonakdar@ippi.ac.ir

$\square$ Krzysztof Formela kformela.ktp@gmail.com; krzysztof.formela@pg.edu.pl

$\triangle$ Mohammad Reza Saeb saeb-mr@icrc.ac.ir

1 Leibniz Institute of Polymer Research Dresden, Hohe Straße 6, 01069 Dresden, Germany

2 Technical University of Dresden, Dresden, Germany

3 School of Chemical Engineering, College of Engineering, University of Tehran, Tehran, Iran

4 Advanced Materials Group, Iranian Color Society (ICS), P.O. Box 1591637144, Tehran, Iran

5 Université de Lorraine, CentraleSupélec, LMOPS 57000 Metz, France

6 Laboratoire Matériaux Optiques, Photoniques et Systèmes, CentraleSupélec, Université Paris-Saclay, 57070 Metz, France
7 Department of Resin and Additives, Institute for Color Science and Technology, P.O. Box: 16765-654, Tehran, Iran

8 Department of Polymer Processing, Iran Polymer and Petrochemical Institute, P.O. Box: 14965-115, Tehran, Iran

9 Department of Polymer Technology, Faculty of Chemistry, Gdańsk University of Technology, G. Narutowicza Str. 11/12, 80-233 Gdańsk, Poland

10 Center of Excellence in Electrochemistry, School of Chemistry, College of Science, University of Tehran, Tehran, Iran

11 Polymer Engineering Department, Faculty of Engineering, Urmia University, Urmia, Iran

12 Color and Polymer Research Center (CPRC), Amirkabir University of Technology, P.O. Box 15875-4413, Tehran, Iran 


\section{Introduction}

Nowadays, disposal of polymer wastes in landfills is a serious challenge in the developing countries, for disposed polymer wastes are permanent contaminants to the local environment including soil and water. This underlines the need for the development of biodegradable polymer composites [1-5]. On the other hand, the competitive market demands a delicate balance between the cost and the performance of the new products. These goals can be partially fulfilled by using natural and waste fillers in polymeric matrice. Past studies have underlined the use of mineral fillers from bio-based and renewable resources including rice husk ash [6, 7], eggshell (ES) powder [8, 9], and cuttlebone $[10,11]$ to tackle the cost problem of products, at the same time as far as possible promote their properties (Fig. 1).

According to the statistical data from Food and Agriculture Organization of the United Nations (FAO), 6.4 million tons of ES are disposed in landfills worldwide in 2010 alone. This data shows an enormous potential of ES for treatment and reuse in polymer products. ES powder has been used as fertilizer and soil conditioner [12], the adsorbent of heavy metals $[13,14]$ and sorption site for $\mathrm{CO}_{2}[15$, 16]. With a growing interest in academia, ES powder has been employed as a biofiller in several polymer matrices including polypropylene (PP) [17], low-density polyethylene (LDPE) [18], and high-density polyethylene (HDPE) [19]. However, the industrial consumption of ES remained limited. According to the literature, ES contributes by
$11 \%$ of the total weight of the egg with its primary component being calcite form of calcium carbonate crystal ( 94\%). Other components of ES include $\mathrm{MgCO}_{3}(\sim 1 \%)$, $\mathrm{Ca}_{3}\left(\mathrm{PO}_{4}\right)_{2}(\sim 1 \%)$, and organic matter $(\sim 4 \%)$ [20]. This abundance of calcium carbonate $\left(\mathrm{CaCO}_{3}\right)$ in the waste ES introduces an excellent source of bio-mineral $\mathrm{CaCO}_{3}$ with possible opportunities to replace mineral-based and synthetic $\mathrm{CaCO}_{3}$ in polymer composites.

ES posesses unique microstructure. The skeleton of $\mathrm{CaCO}_{3}$ in $\mathrm{ES}$ is found to have hierarchical structures; primary nano-particles of $\sim 10 \mathrm{~nm}$ loosely to give a porous and rough texture. The observed morphologies include submicrospheres, nano-rods, and rhombohedral-cleavage pattern and slices that are elaborately arranged in a surface layer by the nature. The palisade layer and mammillary layer lie them along the radial directions. From the Fig. 2 one can conclude that the pore system exhibits a three-level hierarchy: nano-scale pores (between nano-rods and primary nano-particles), sub-micro-scale pores ("bubble pores"), and micro-scale pores (opening of "gas pores") [21]. Such a structure has a message that ES should have good interaction with polymer resins thanks to its porous microstructure.

The performance of reinforcing agents in polymer systems depends on their compatibility with polymer chains [22-24]. As such, the surface of the particles is usually modified to promote polymer-filler interactions [25-28]. Additionally, surface functionalization by using organic materials, may lower the surface energy value of the mineral phase and reduce the possibility of agglomeration of the particles [29, 30]. In $\mathrm{CaCO}_{3}$, for example, stearic acid has been frequently used for such purpose [31]. Similarly,
Fig. 1 Common bio-based waste fillers used for the development of biodegradable polymer composites. Amongst various bio-filler resources, widely-used ES exhibits unique properties

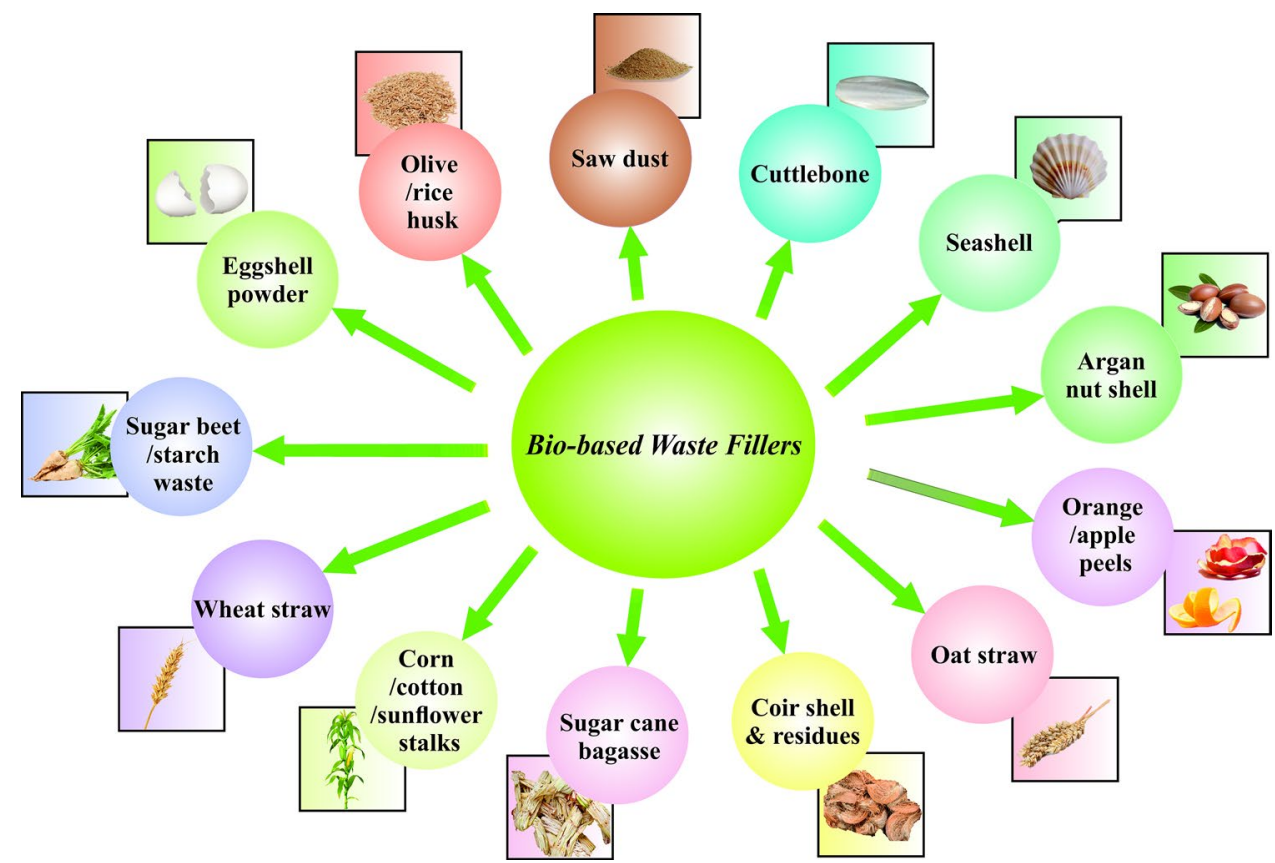




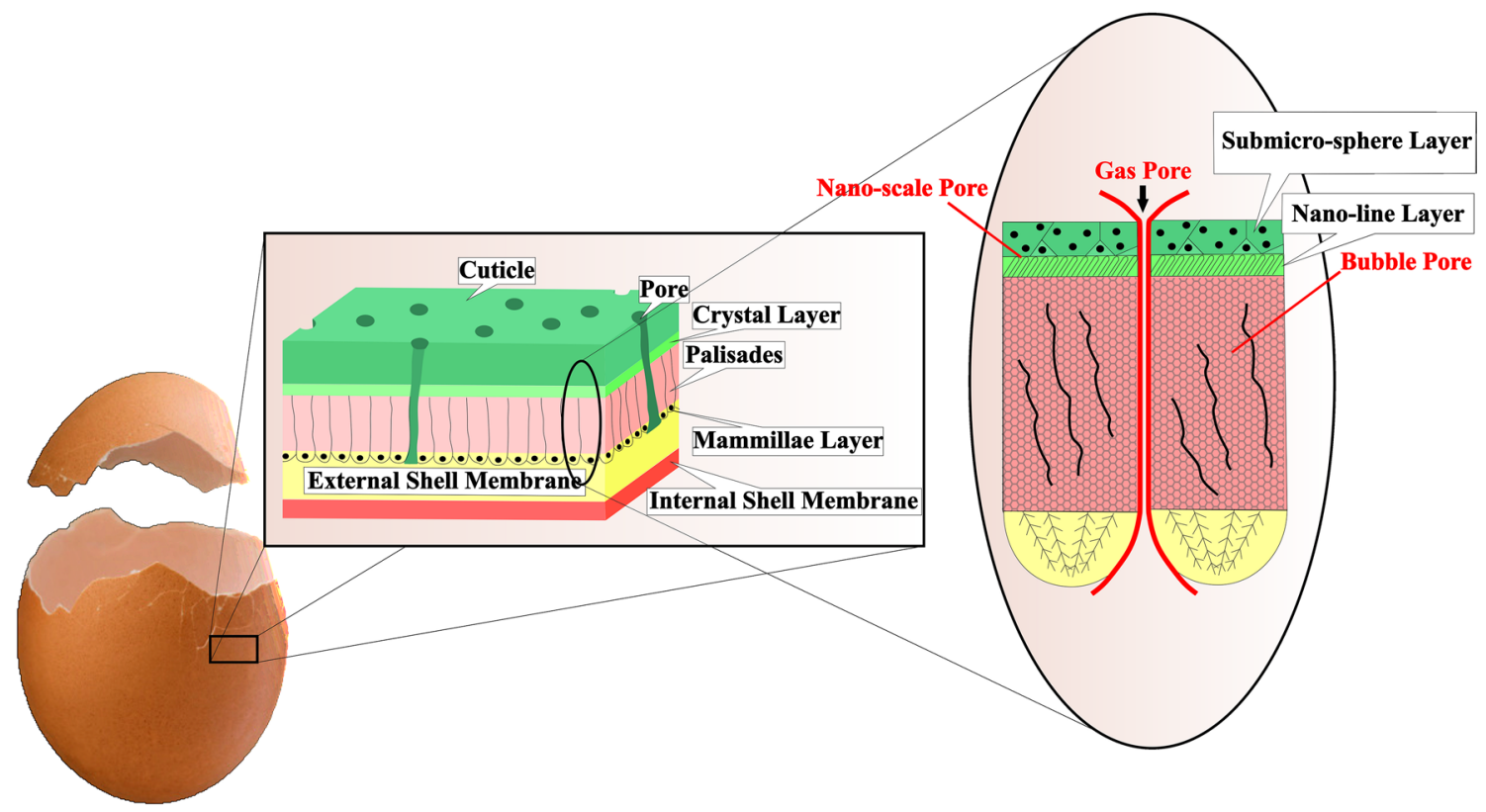

Fig. 2 Illustration of ES structure and its three-level pore system

ES powder has been treated with stearic acid to improve the mechanical properties of polypropylene (PP) composites. The Young's modulus of PP composites containing $40 \mathrm{wt} \%$ of treated ES was improved by 200\%, whereas the crystallinity of PP composites containing pristine ES powder remained almost unchanged [32]. Kumar et al. [33] used isophthalic acid in surface functionalization of ES and reported 3-18\% improvement in tensile modulus of the PP composite compared to the one containing pristine ES or mineral-based $\mathrm{CaCO}_{3}$. Pimelic acid (PA) has also been used to modify ES powder. It was shown that ES/ $\beta$-PP biocomposite could be prepared through melt compounding of PP and ES. The modified ES caused high efficiency and selectivity for $\beta$-PP formation. The modification of PA promoted the dispersion state of ES in PP matrix by decreasing the interfacial tension. Although the addition of PA-modified ES has slightly deteriorated tensile and flexural properties of PP, it has increased the impact strength of PP by $228 \%$ compared to that of pure PP [17]. The ES powder has also been used as a reinforcing filler in elastomers such as natural rubber (NR), acrylonitrile butadiene rubber (NBR), styrene-butadiene rubber (SBR), and epoxidized natural rubber (ENR) [34]. In a previous work, curing characteristics and mechanical properties of NBR, NR, and SBR composites filled with ES powder were discussed [35]. It was revealed that incorporation of ES into rubber matrix decreases the optimum cure time and hereby improves the mechanical properties of NR, NBR, and SBR composites thanks to porous structure of ES particles compared to $\mathrm{CaCO}_{3}$-filled composites [32]. The likely interactions between ES and NBR chains are depicted in Fig. 3.

So far, a growing body of work in the literature has sought to examine the possibility of replacing $\mathrm{CaCO}_{3}$ with bio-waste ES. The results, although promising, are far from complete. It is important to note that studies in the past have mainly been focused on thermoplastics, and limited reports exist on thermosets and elastomeric composites. In recent studies, some important aspects of surface modification of ES powder towards the elastomeric compounds including NR, SBR, and NBR were discussed $[32,33]$. Specifically, the effect of surface modification, filler loading, and particle size distribution on the curing and thermo-mechanical properties of NR, SBR, and NBR rubbers containing $\mathrm{CaCO}_{3}$ and various types of $\mathrm{ES}$ have been comprehensively reported.

In this work, poly(vinyl pyrrolidone-co-maleic acid-coacrylic acid) terpolymer was used instead of the conventional use of small molecules in surface modification of the fillers to improve curing behavior and mechanical properties of NBR composites. The efficiency of the surface functionalization procedure using FTIR and TGA measurements were discussed. The correlation between surface functionality, curing behavior and mechanical properties of the compounds were also studied. This work is an attempt towards the manifestation of biowaste ES-based rubber composites for engineering applications. 
Fig. 3 Possible formation site for interaction of NBR with ES

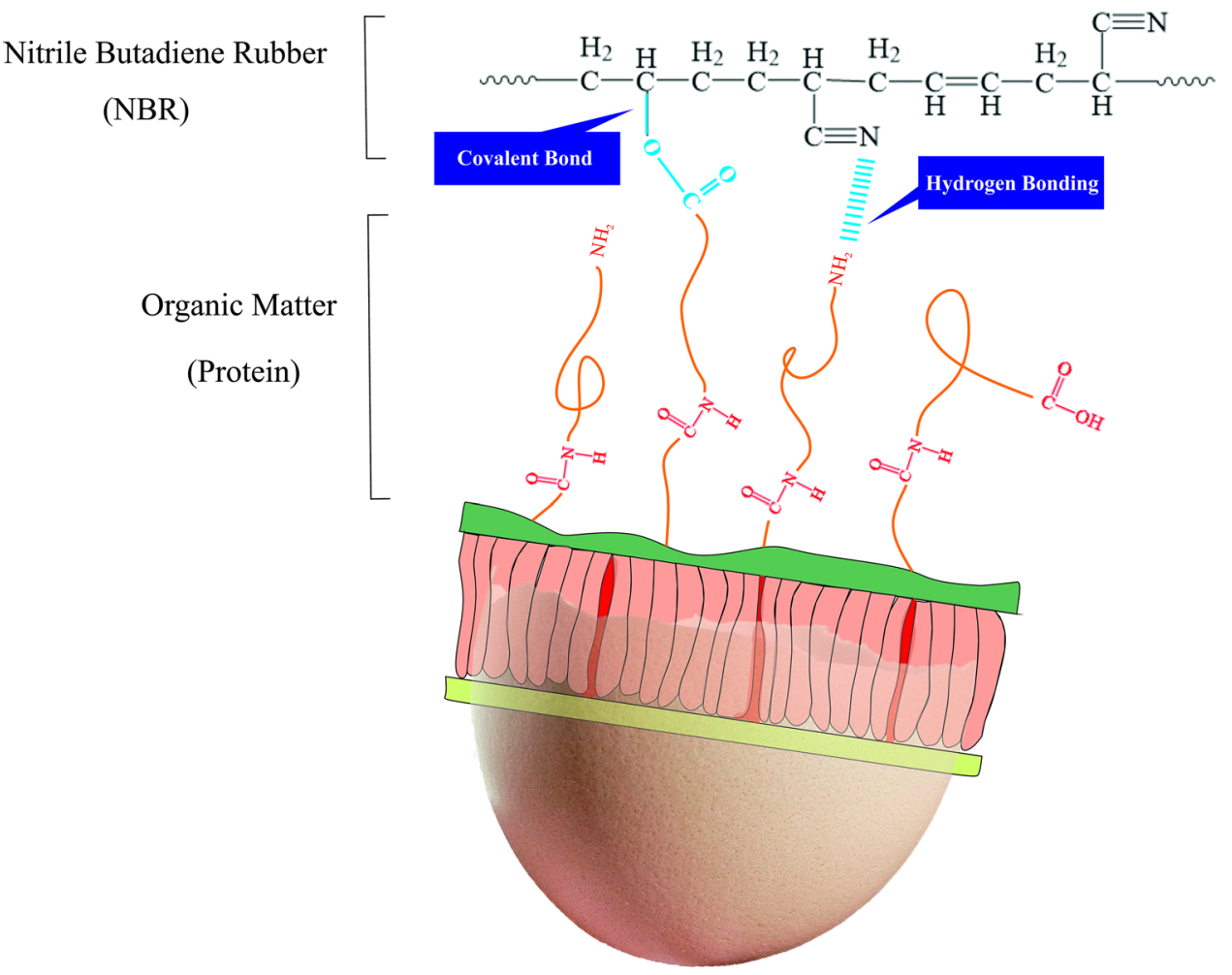

Table 1 Average particle size and surface area of pristine and modified fillers studied here

\begin{tabular}{llll}
\hline Filler type & Trade name & $\begin{array}{l}\text { Average particle } \\
\text { size }(\mathrm{nm})\end{array}$ & $\begin{array}{l}\text { Surface } \\
\text { area } \\
\left(\mathrm{m}^{2} / \mathrm{g}\right)^{\mathrm{a}}\end{array}$ \\
\hline $\mathrm{CaCO}_{3}$ & ALBAFIL $^{\circledR}$ PCC & 700 & 1.95 \\
$\mathrm{mCaCO}_{3}$ & - & 660 & 2.40 \\
$\mathrm{ES}$ & - & 690 & 4.50 \\
$\mathrm{mES}$ & - & 570 & 5.55 \\
\hline
\end{tabular}

${ }^{\mathrm{a}}$ Measured using BET

\section{Experimental}

\section{Materials}

Acrylonitrile butadiene rubber (Perbunan 1846F) known took credit for seals at extremely low (down to $-40{ }^{\circ} \mathrm{C}$ ) and high (up to $120^{\circ} \mathrm{C}$ ) temperatures. It contains $18 \mathrm{wt} \%$ acrylonitrile content was provided by Lanxess (Germany). The Mooney viscosity of rubber at $100{ }^{\circ} \mathrm{C}$ was $41 \mathrm{ML}$ $(1+4)$, and the glass transition temperature $\left(T_{g}\right)$ was $-35{ }^{\circ} \mathrm{C}$. Sulfur and mercaptobenzothiazole sulfenamide (MBTS) were used as vulcanizing agent and accelerator, respectively, and obtained from Lanxess (Germany). The activating system including zinc oxide and stearic acid was supplied by Acros Organics (Belgium). The untreated calcium carbonate GR102066 was purchased from Bayer Chemicals (Germany). The micro-size precipitated $\mathrm{CaCO}_{3}$ particle with the trade name of ALBAFIL® PCC was provided by the CARY Co. (USA). Chicken ES wastes were collected from local farms in Tehran, Iran. Table 1 summarizes some properties of these fillers.

\section{Surface Functionalization of Particles}

Surface functionalization of fillers with terpolymer was done using a two-step procedure (Fig. 4). In the first step, $9.8 \mathrm{~g}$ $(0.1 \mathrm{~mol})$ maleic anhydrate, $7.2 \mathrm{~g}(0.1 \mathrm{~mol})$ acrylic acid, and $23 \mathrm{~g}(0.21 \mathrm{~mol})$ vinyl pyrrolidone were added to $60 \mathrm{ml}$ water at $50{ }^{\circ} \mathrm{C}$ to prepare a terpolymer by aqueous radical polymerization. Then, $0.08 \mathrm{~g}$ TBHP (tert-butyl hydroperoxide) and $0.09 \mathrm{~g}$ SFS (formaldehyde sulfoxilate) were dissolved into the resulting solution and stirred for $1 \mathrm{~h}$ at $50{ }^{\circ} \mathrm{C}$, followed by $2 \mathrm{~h}$ stirring at $75^{\circ} \mathrm{C}$. The obtained product was a clear solution of $40 \mathrm{wt} \%$ solid terpolymer, used for the surface functionalization of $\mathrm{ES}$ and $\mathrm{CaCO}_{3}$. In the next step, $40 \mathrm{~g}$ of terpolymer and $100 \mathrm{~g}$ of $\mathrm{CaCO}_{3}$ were dispersed in $450 \mathrm{~g}$ of water at room temperature for $12 \mathrm{~h}$ with mechanical stirring to graft the terpolymer on the filler surface. Subsequently, the mixture was heated at $80{ }^{\circ} \mathrm{C}$ in a vacuum oven without filtration, and the obtained solids were grounded. The same procedure was followed for the ES powder as well. All chemical compounds used for surface treatment were supplied by Merck and used as received without further 
Fig. 4 Schematic illustration of the synthesis of poly(vinyl pyrrolidone- $\mathrm{co}$-maleic acid-coacrylic acid) terpolymer. This polymer is subsequently used to modify $\mathrm{ES}$ and $\mathrm{CaCO}_{3}$ fillers

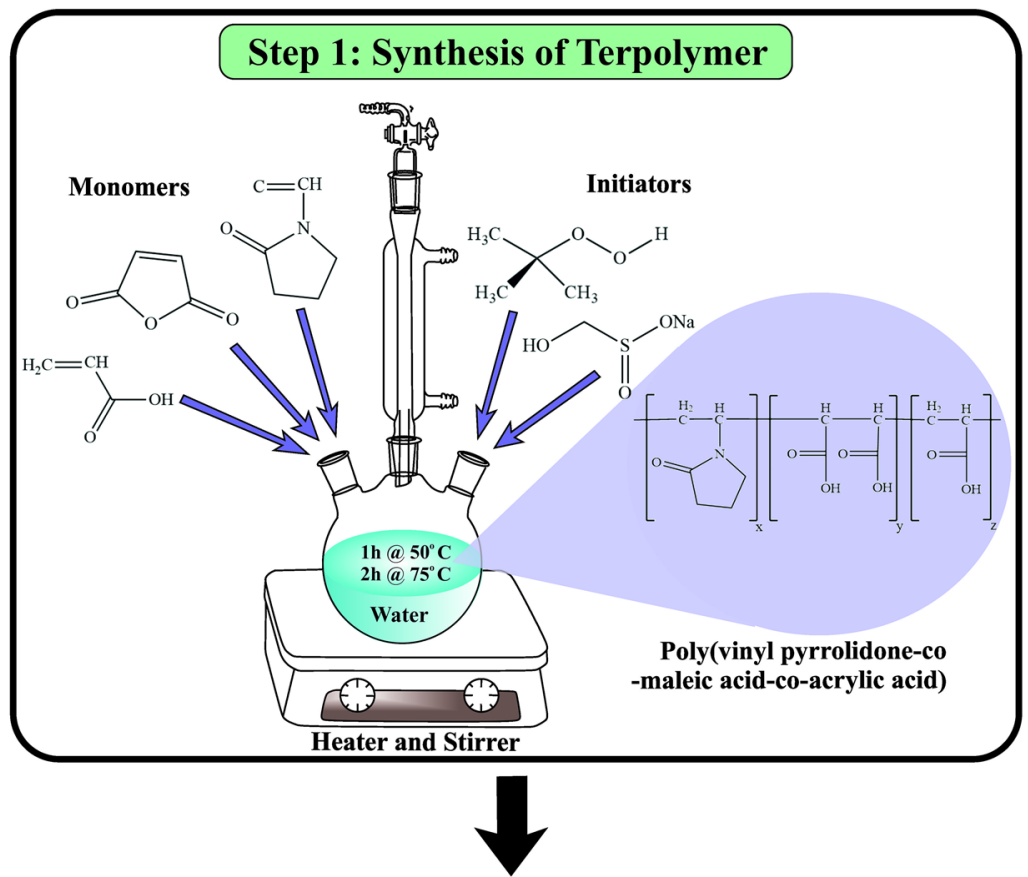

Step 2: Surface Modification
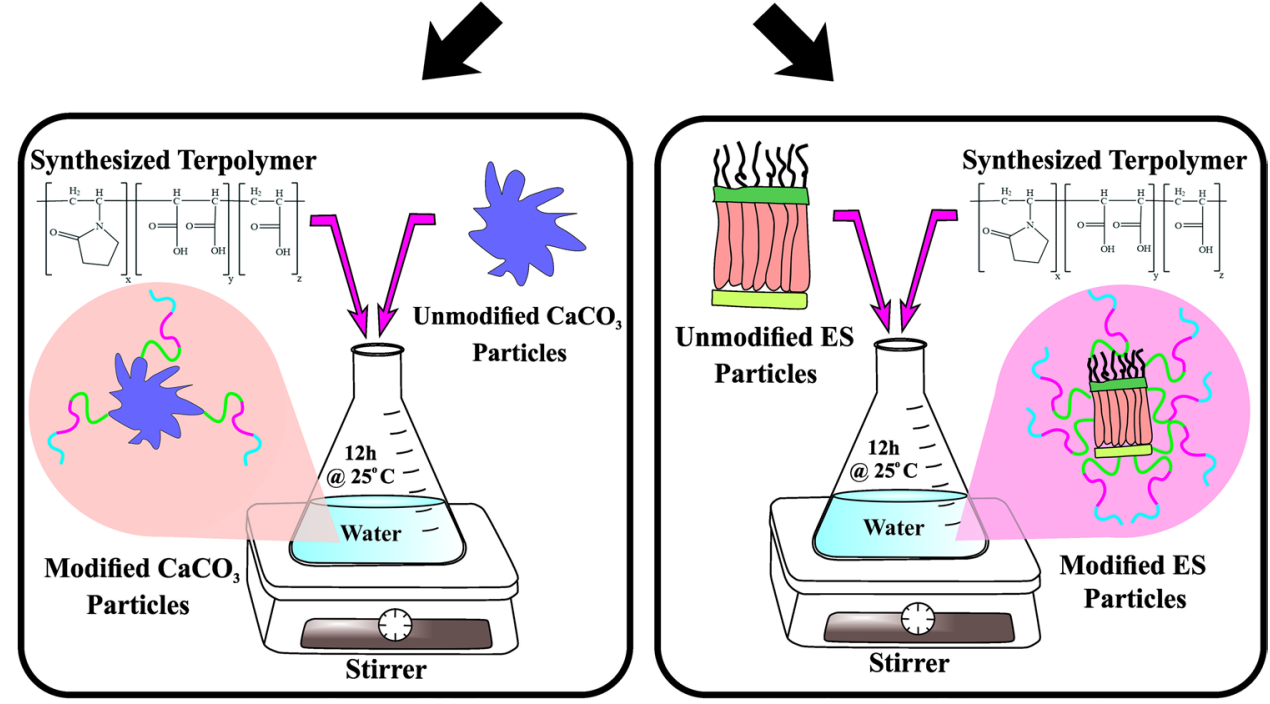

purification. The functionalized $\mathrm{ES}$ and $\mathrm{CaCO}_{3}$ will be denoted hereafter as $\mathrm{mES}$ and $\mathrm{mCaCO}_{3}$, respectively.

\section{Preparation of NBR Composites}

The NBR matrix was first masticated for 1 min to reduce its viscosity in a laboratory size two-roll mixing mills (Polymix 110L, size: $203 \times 102 \mathrm{~mm}$ Servitech $\mathrm{GmbH}$, Wustermark, Germany) at $60{ }^{\circ} \mathrm{C}$. Zinc oxide, stearic acid, and the fillers were added to the rubber and mixed for homogenization during 10 15 min depending on the quantity of the fillers. Next, the curing system was mixed and milled with the resulting composites at $40{ }^{\circ} \mathrm{C}$ for 10 min before curing at
Table 2 The compounding formulation of the samples

$160{ }^{\circ} \mathrm{C}$ under pressure of $150 \mathrm{kN}$ in a compression molding machine to obtain sheets of $2 \mathrm{~mm}$ thickness. Table 2 lists the formulation based on $100 \mathrm{phr}$ NBR. We changed the filler 
content from 5 to $50 \mathrm{phr}$ to study the performance of the fillers at various contents.

\section{Characterization and Testing}

To verify the functionalization of fillers, Fourier transform infrared (FTIR) spectral analysis was utilized using Brucker Vertex $80 \mathrm{~V}$ spectrophotometer over the wavelength range of $400-4000 \mathrm{~cm}^{-1}$. To prepare the samples for the test, filler powders were mixed with $\mathrm{KBr}$ and pressed into a pellet. Thermogravimetric analyzer TGA Q5000 from TA Instruments was also used to investigate the decomposition temperature and weight loss of the unmodified and modified fillers. The measurements were performed at a heating rate of $10{ }^{\circ} \mathrm{C} / \mathrm{min}$ under nitrogen atmosphere up to $600{ }^{\circ} \mathrm{C}$. Tensile properties of the samples were determined using a universal testing machine (Zwick 1456, Z010, Ulm, Germany) with DIN S2 dumbbell samples. The strain was applied at a rate of $200 \mathrm{~mm} / \mathrm{min}$. In all cases, tensile tests were carried out on five dumbbell specimens. Average values measured and the standard deviations were reported. Investigations of curing characteristics were done using rheometric studies in a moving die rheometer Göttfert Elastograph Vario 67.03. Optimal curing time was considered as the time for the rubber to reach $90 \%$ of its maximum torque.

\section{Results and Discussions}

\section{Assessment of the Surface Treatment of mES and $\mathrm{mCaCO}_{3}$}

FTIR spectra of the untreated and functionalized particles were measured in order to confirm the success of the surface treatment procedure (Fig. 5). The FTIR spectrum of the $\mathrm{CaCO}_{3}$ shows distinct adsorption peaks at 713, 862, 1164 , and $1473 \mathrm{~cm}^{-1}$, related to the in-plane bending vibration, out-of-plane bending vibration, symmetric stretch, and the asymmetric stretch of carbonate $\left(\mathrm{CO}_{3}^{2-}\right)$, respectively (Fig. 5a). In the case of $\mathrm{mCaCO}_{3}$, the peaks at $3400 \mathrm{~cm}^{-1}$ are attributed to the hydroxyl $(-\mathrm{OH})$ functional groups of the terpolymer. This peak confirms the surface modification of the filler. The FTIR spectra of pristine ES (Fig. 5b) shows two adsorption peaks at 3400 and $2514 \mathrm{~cm}^{-1}$ corresponding to the stretching vibration of amide $(-\mathrm{N}-\mathrm{H})$ and thiol $(-\mathrm{S}-\mathrm{H})$ bonds of cysteine respectively. A typical protein that exists in the mammillary layer of ES. The peaks at 1418,875 , and $712 \mathrm{~cm}^{-1}$ correspond to other proteins in the membrane. Notably, FTIR spectra of mES reveal a strong adsorption peak at $3400 \mathrm{~cm}^{-1}$ due to the presence of $-\mathrm{OH}$ groups on the filler surface.

Thermal behavior of the samples was performed to further evaluate the surface treatment of fillers. TGA thermograms of $\mathrm{ES}$ and $\mathrm{CaCO}_{3}$ fillers along with a summary of the characteristic features including onset temperature of major decomposing $\left(\mathrm{T}_{\text {onset }}\right)$, first and second maximum decomposition temperature $\left(\mathrm{T}_{\max }\right)$, and char content at $590{ }^{\circ} \mathrm{C}(\%)$ are shown in Fig. 6. Dotted lines in this figure are derivative if TGA, which confirm occurrence of degradation by showing intensive peaks instead of shoulders in TGA thermograms. Accordingly, two steps in the TGA curve of unmodified ES are recognized: (i) weight loss of pristine ES in range of temperature from $260-400{ }^{\circ} \mathrm{C}$ with a maximum rate of weight loss at $300{ }^{\circ} \mathrm{C}$ corresponding to decomposition of organic components of the shell membrane, and (ii) de-carbonation of calcium carbonate around $500 \sim 600{ }^{\circ} \mathrm{C}$. A new peak, at about $160{ }^{\circ} \mathrm{C}$, appears for the surface-functionalized $\mathrm{ES}$ and $\mathrm{CaCO}_{3}$ fillers due to decomposition of the terpolymer molecules attached on the surface. The TGA thermograms of $\mathrm{mES}$ shows a steeper weight loss compared to $\mathrm{mCaCO}_{3}$
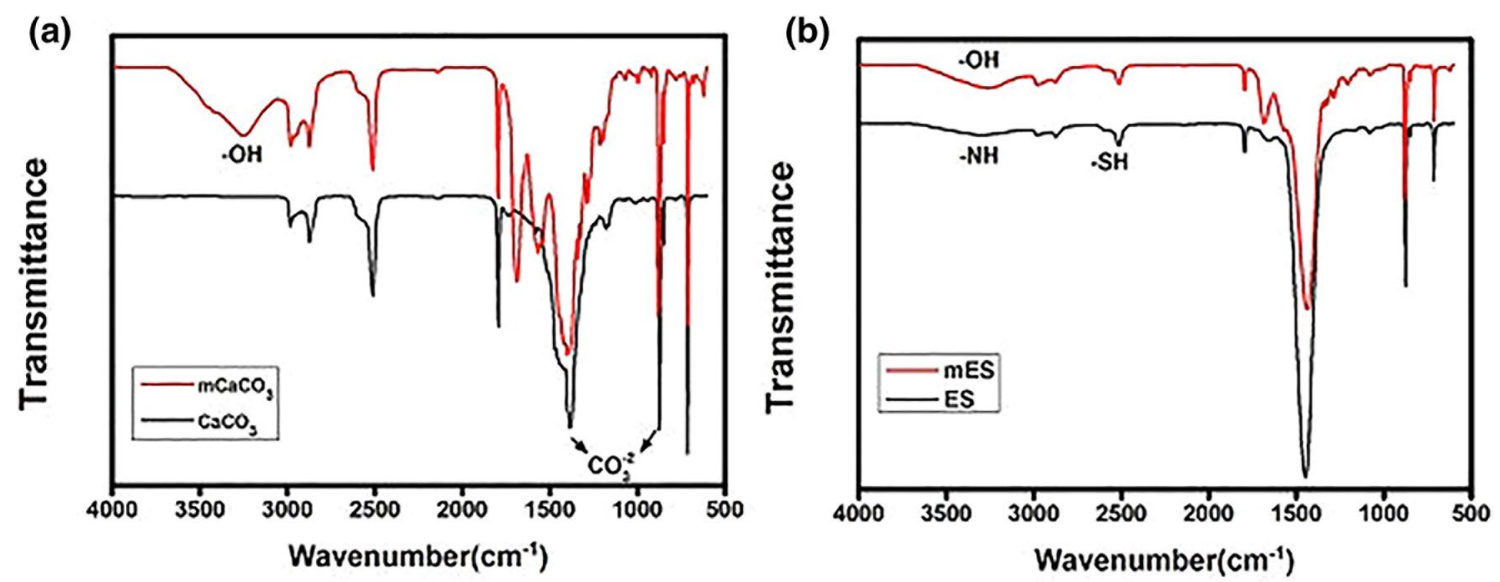

Fig. 5 FTIR spectra of $\mathbf{a} \mathrm{CaCO}_{3}$ and $\mathrm{mCaCO}_{3} \mathbf{b} \mathrm{ES}$ and $\mathrm{mES}$. The peaks around $3400 \mathrm{~cm}^{-1}$ correspond to -OH functional group in mES and $\mathrm{mCaCO}_{3}$ which confirm the success of the surface treatment procedure 


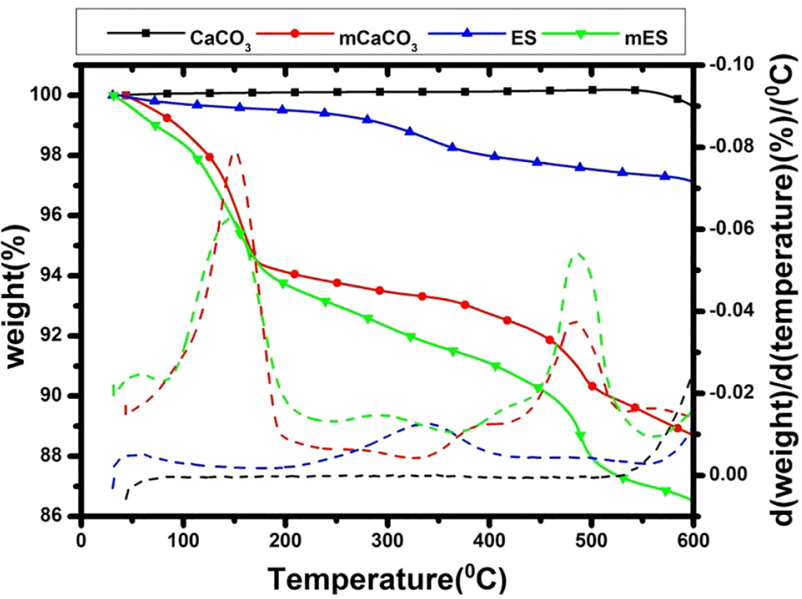

\begin{tabular}{ccccc}
\hline Specimen & $\begin{array}{c}\mathrm{T}_{\text {onset }} \\
\left({ }^{\circ} \mathrm{C}\right)\end{array}$ & \multicolumn{2}{c}{$\begin{array}{c}\text { Maximum Decomposition } \\
\text { Temperature }\left({ }^{\circ} \mathrm{C}\right)\end{array}$} & $\begin{array}{c}\text { Residue at 590 } \\
(\%)\end{array}$ \\
\cline { 3 - 4 } & & First & second & \\
\hline $\mathrm{CaCO}_{3}$ & 534 & & & 99.64 \\
$\mathrm{mCaCO}_{3}$ & 43 & 150 & 483 & 88.72 \\
$\mathrm{ES}$ & 213 & 338 & & 97.13 \\
$\mathrm{mES}$ & 83 & 144 & 486 & 86.52 \\
\hline
\end{tabular}

Fig. 6 Thermogravimetric curves of $\mathrm{ES}, \mathrm{mES}, \mathrm{CaCO}_{3}$, and $\mathrm{mCaCO}_{3}$. The multi-step weight loss of modified fillers over the heating process confirms the attachment of terpolymer to the filler surface. Dotted lines are derivatives of TGA

due to decomposition of the organic membrane at low temperatures (Fig. 6). The char content of $\mathrm{mES}$ (or $\mathrm{mCaCO}_{3}$ ) at $590{ }^{\circ} \mathrm{C}$ was also lower than pristine $\mathrm{ES}$ (or $\mathrm{CaCO}_{3}$ ) due to decomposition of terpolymer molecules during the heating. On other words, chemical modification of ES reside along the ES structure which contribute in the decomposition during heating.

\section{Rheometric Cure Characteristics}

We hypothesize that the organic components of the ES and the terpolymer used for surface-modification of the filler may influence the cure characteristics of NBR-based composites rubber. To confirm these possible effects, we study the rheometric behavior of NBR composites containing various amounts of fillers (Fig. 7). Overall, the addition of 5 or $10 \mathrm{phr}$ of fillers only marginally affects the cure behavior of the compounds, whereas higher contents of fillers considerably increase the maximum torque and decrease the curing time, especially for $\mathrm{mES}$ and $\mathrm{mCaCO}_{3}$. Furthermore, in the case of $\mathrm{mCaCO}_{3}$ or $\mathrm{mES}$, the maximum torque increased compared to the unfilled NBR or composites filled with unmodified fillers. This behavior indicates an enhancement of the cross-link density. It is worthy of note that the curing reaction of NBR matrix occurs faster in the presence of modified fillers, which show better vulcanization characteristics of the modified fillers.

The scorch time $t_{10}$ (the corresponding time when torque reaches to $10 \%$ of the maximum value) and the optimum cure time $t_{90}$ were analyzed to quantify the effect of filler type and the filler content on the cure characteristics of NBR composites (Fig. 8). The composites containing the mES and $\mathrm{mCaCO}_{3}$ fillers show a lower scorch time and a lower optimum cure time compared to those containing unmodified fillers. These results indicate that the terpolymer would likely contribute in the vulcanization kinetics of the composites. In other words, the samples that contain modified fillers cause acceleration of the vulcanization process [36].

\section{Young's Modulus}

It is well-documented that the mechanical properties of the vulcanized rubbers are mainly controlled by the type of inclusions, the filler content, and particularly the strengths of the interfacial interactions between the rubber matrix and the fillers. To understand the role of $\mathrm{ES}$ and $\mathrm{CaCO}_{3}$ on the Young's modulus of the NBR composites, we study the mechanical properties of the composites (Fig. 9). Overall, Young's modulus of the composites increase by increasing the filler content, independent of filler type or surface modification. The formation of a filler network above a percolation threshold further improves the Young's modulus at high filler contents [37]. While the Young's modulus of mES containing NBR composites is always higher than the ones filled with pristine ES, the Young's modulus of $\mathrm{mCaCO}_{3}$ containing systems were lower than the ones filled with the unmodified $\mathrm{CaCO}_{3}$ (Fig. 9). In general, the small and well-dispersed particles of the ES facilitate an improvement of the Young's modulus [8, 38]. Surface modification of the ES particles improves the filler-rubber interactions leading to higher Young's modulus. The different behaviors of the $\mathrm{mES}$ and $\mathrm{mCaCO}_{3}$ fillers could be explained based on the nature of the interactions between the terpolymer and the surface of the fillers, and the surface topology of the fillers. Fig. 11 illustrates the possible interactions leading to different reinforcement behaviors of NBR composites filled by as-received and modified $\mathrm{ES}$ and $\mathrm{CaCO}_{3}$ fillers. Accordingly, an enhancement in the Young's modulus of NBR occurred upon addition of $\mathrm{mES}$, whereas modification of $\mathrm{CaCO} 3$ adversely affected the Young's modulus. This can be explained by the possible mechanism of reinforcement of mES and mCaCO3. Whwn incorporating mES into the NBR, hydrogen and covalent bond between mES and NBR chains are formed 

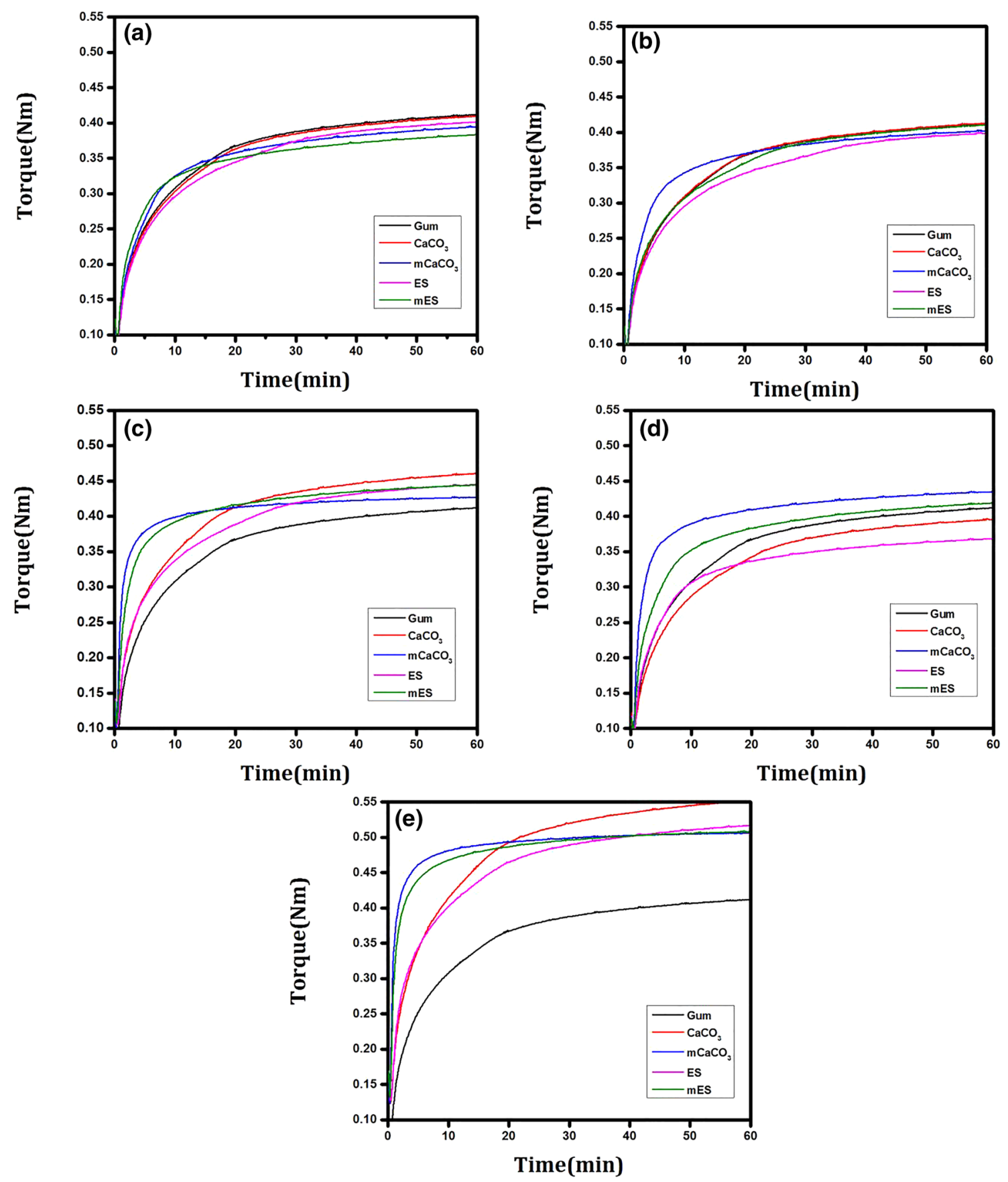

Fig. 7 Rheometric curves of NBR composites containing a 5, b 10, c 15, d 30, and e 50 phr of different fillers. The maximum torque increases upon introduction of the modified fillers to NBR due to possible intervention of functional groups of the terpolymer with the curing agents

expectedly, which improve the Young's modulus. However, modification of $\mathrm{CaCO} 3$ impeded the formation of van der Waals bonds between the filler and elastomer chains, which inversely decreased Young's modulus compared to pristine $\mathrm{CaCO} 3$. Moreover, it was likely that surface functionalization of ES might improve the dispersion state of ES in NBR matrix, as evidenced by mechanical properties, while for $\mathrm{mCaCO}_{3}$ more aggregated clusters were expectedly formed. Understanding the nature of these interactions will be the subject of future studies. 
Fig. 8 Scorch times $\left(t_{10}\right)$ of $\mathbf{a}$ $\mathrm{CaCO}_{3}$ composites and b ES composites and optimum cure times $\left(\mathrm{t}_{90}\right)$ of $\mathbf{c} \mathrm{CaCO}_{3}$ composites and $\mathbf{d}$ ES composites as a function of filler content
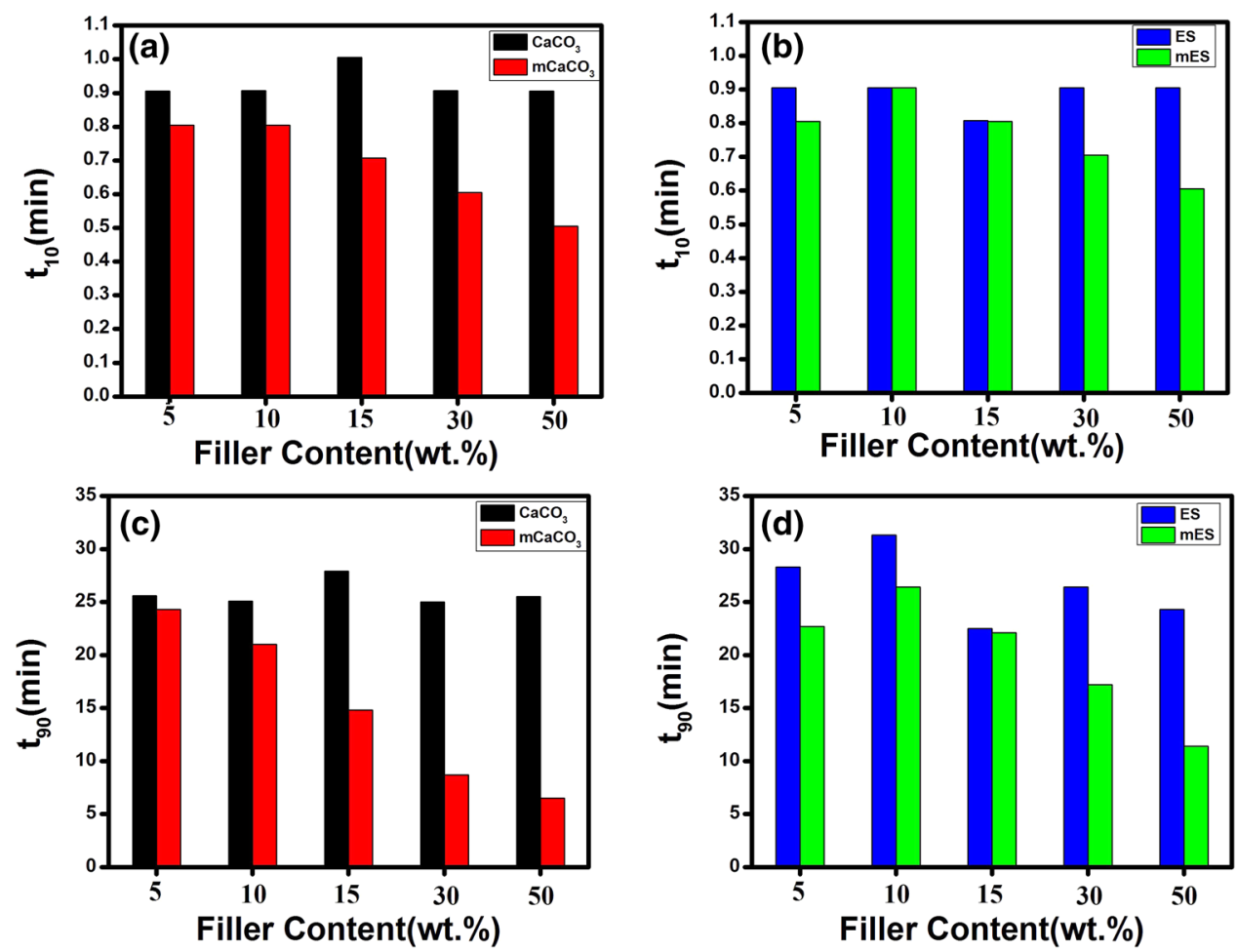

(a)

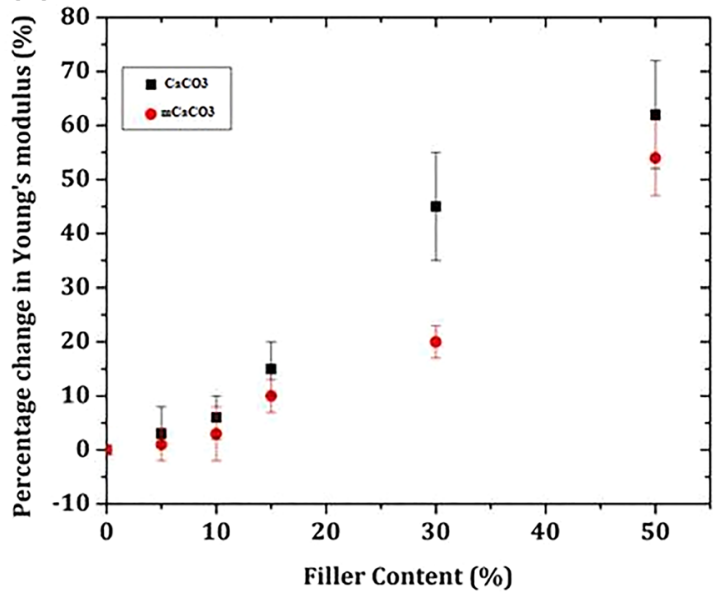

(b)

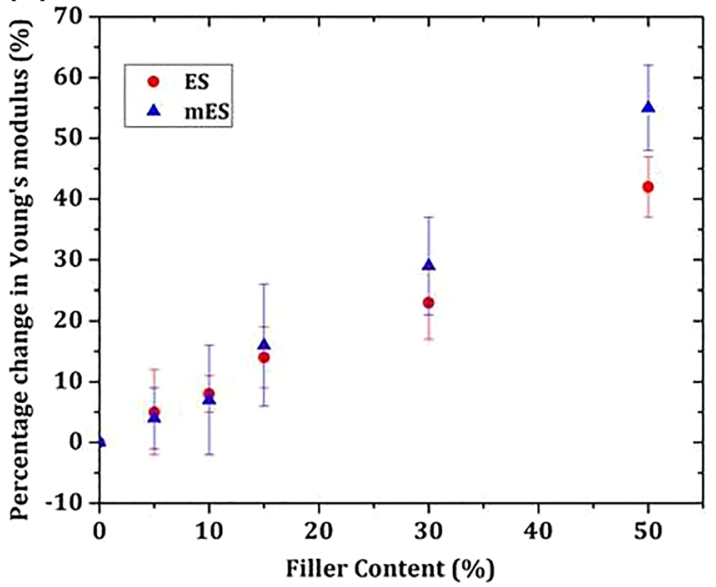

Fig. 9 Percentage change in Young's modulus of NBR composites filled with a modified and unmodified $\mathrm{CaCO}_{3} \mathbf{b}$ modified and unmodified ES

The reinforcing capability of fillers may be understood using Guth-Gold equation [39, 40], where the improvement in Young's modulus of filled composites is expressed as a function of filler volume fraction, and filler shape:

$\frac{M}{M_{0}}=1+0.67 f+1.62 f^{22}$
In this equation, $M$ is the Young's modulus of the filled composite, $M_{o}$ is the Young's modulus of the unfilled vulcanizate, $\phi$ is the volume fraction of the filler, and $f$ is the shape factor [35]. The shape factor $f$ for non-spherical fillers is generally higher than unity. To obtain the shape factor $f$, we fit the Young's moduli of the compounds to the Guth-Gold equation (Fig. 10). Because the surface modification of $\mathrm{mCaCO}_{3}$ worsens its reinforcing effect, 


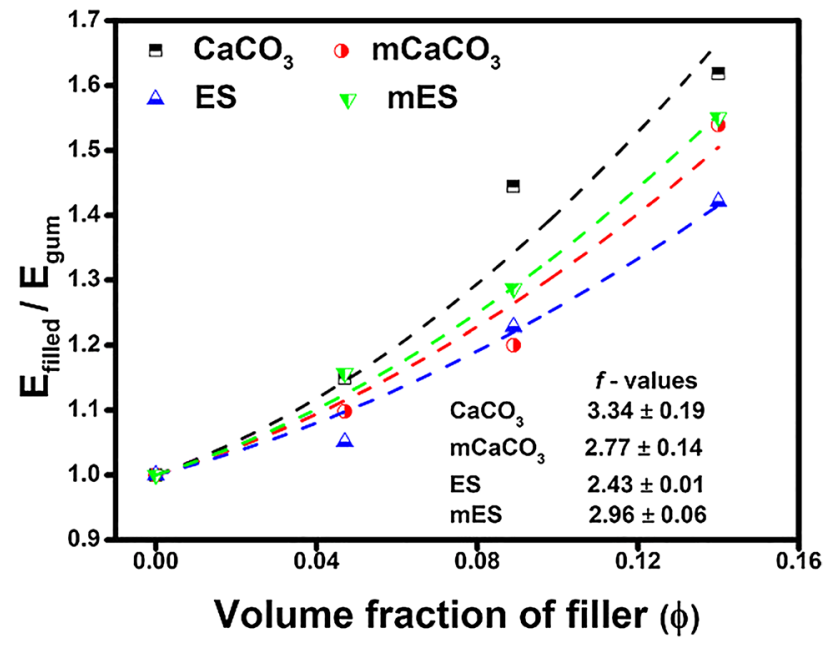

Fig. 10 Guth-Gold plot demonstrating the reinforcing effects of the used fillers. It is obvious that $\mathrm{mCaCO}_{3}$ negatively influences the reinforcement, whereas $\mathrm{mES}$ shows a positive effect

we obtain lower $f$ values for $\mathrm{mCaCO}_{3}$ compared to pristine filler. This fact agrees well with the trends observed in Fig. 9a. On the other hand, modification of ES has proved to be effective, as there is an increase in $f$ value from 2.4 to 2.96 due to surface modification of filler with terpolymer.
This substantial improvement confirms an efficient dispersion of the mES in the NBR matrix.

\section{Conclusions}

In this work, biowaste eggshell and calcium carbonate powders were applied as fillers in preparation of NBR composites. It was observed that chemical modification of the surface of $\mathrm{CaCO}_{3}$ and ES has a limited or no effect on the mechanical properties (tensile modulus and elongation at break) of NBR composites at low loading levels as confirmed by determination of shape factor of fillers that demonstrates reinforcing effect of the filler, while a completely different effect on high loadings. Modification of $\mathrm{CaCO}_{3}$ deteriorates elongation at break of NBR, but eggshell surface modification by terpolymer increased interaction between the filler and polymer chains. Such contradictive behavior was attributed to the role of peptide groups in the eggshell and carboxylic groups of terpolymer, which synergistically enhance filler-polymer interaction in terms of hydrogen and covalent bonding in eggshell powder-filler NBR unlike their effects in the case of $\mathrm{CaCO}_{3}$-filled rubbers. Thus, it can be corroborated that surface functionalization of biowaste eggshell provides this additive with a very high
Fig. 11 Possible mechanisms for different reinforcement behaviors of composites filled with $\mathbf{a} \mathrm{CaCO}_{3}, \mathbf{b} \mathrm{mCaCO}_{3}$, c ES, and $\mathbf{d}$ mES fillers
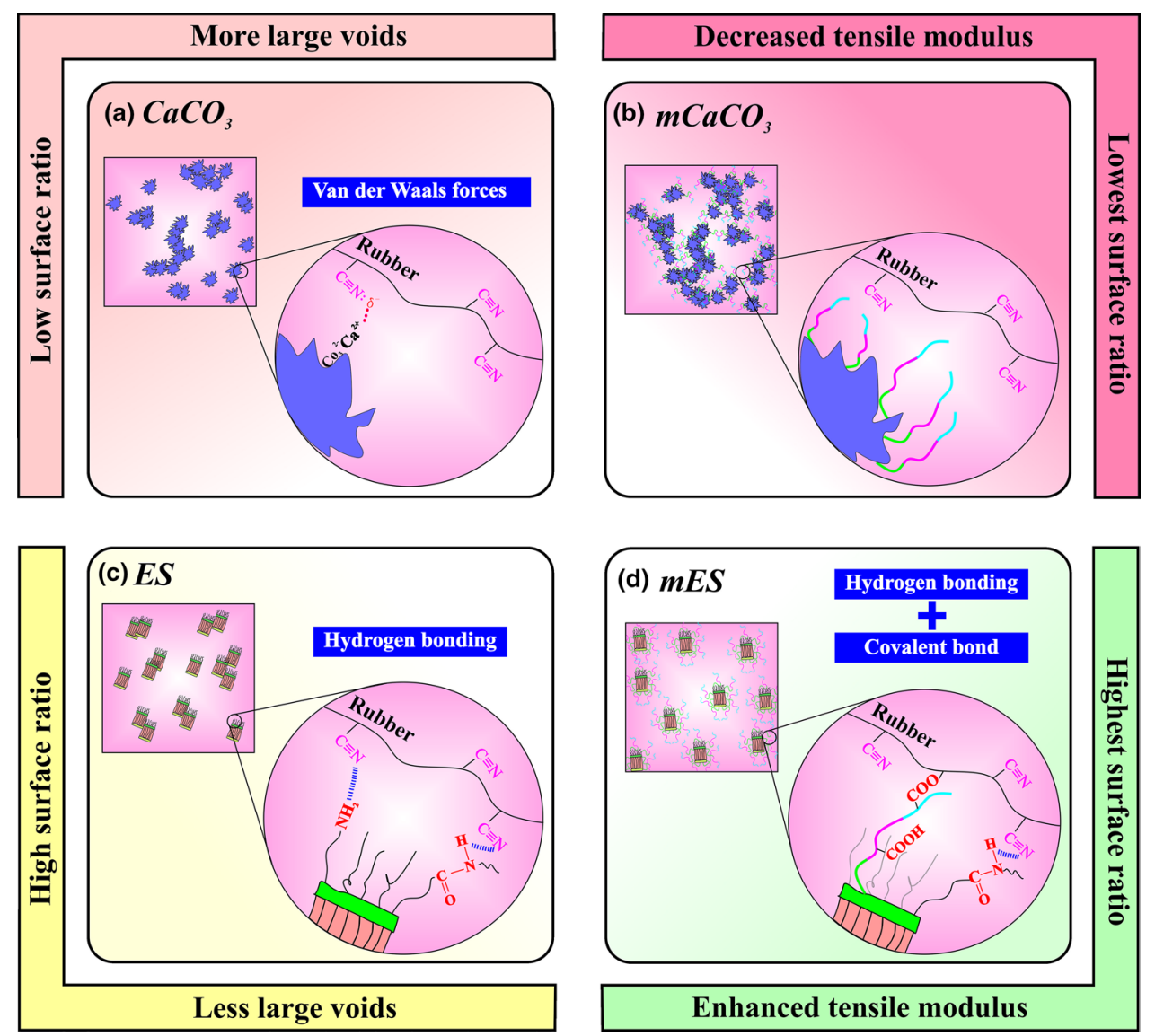
potential for improvement of mechanical properties of rubber compounds.

Open Access This article is distributed under the terms of the Creative Commons Attribution 4.0 International License (http://creativeco mmons.org/licenses/by/4.0/), which permits unrestricted use, distribution, and reproduction in any medium, provided you give appropriate credit to the original author(s) and the source, provide a link to the Creative Commons license, and indicate if changes were made.

\section{References}

1. Hejna A, Formela K, Saeb MR (2015) Processing, mechanical and thermal behavior assessments of polycaprolactone/agricultural wastes biocomposites. Ind Crop Prod 76:725-733

2. Rahmati M, Milan PB, Samadikuchaksaraei A, Goodarzi V, Saeb MR, Kargozar S, Kaplan DL, Mozafari M (2017) Ionically crosslinked thermoresponsive chitosan hydrogels formed in situ: a conceptual basis for deeper understanding. Macromol Mater Eng 302:1700227

3. Mysiukiewicz O, Barczewski M (2019) Utilization of linseed cake as a postagricultural functional filler for poly (lactic acid) green composites. J Appl Polym Sci 136:47152

4. Formela K, Hejna A, Piszczyk Ł, Saeb MR, Colom X (2016) Processing and structure-property relationships of natural rubber/ wheat bran biocomposites. Cellulose 23:3157-3175

5. John MJ, Thomas S (2008) Biofibres and biocomposites. Carbohydr Polym 71:343-364

6. Kim HS, Yang HS, Kim HJ, Park HJ (2004) Thermogravimetric analysis of rice husk flour filled thermoplastic polymer composites. J Therm Anal Calorim 76:395-404

7. Hwang CL, Huynh TP (2015) Effect of alkali-activator and rice husk ash content on strength development of fly ash and residual rice husk ash-based geopolymers. Constr Build Mater 101:1-9

8. Toro P, Quijada R, Arias JL, Yazdani-Pedram M (2007) Mechanical and morphological studies of poly(propylene)-filled eggshell composites. Macromol Mater Eng 292:1027-1034

9. Baláž M, Zorkovská A, Fabián M, Girman V, Briančin J (2015) Eggshell biomaterial: characterization of nanophase and polymorphs after mechanical activation. Adv Powder Technol 26:1597-1608

10. Poompradub S, Ikeda Y, Kokubo Y, Shiono T (2008) Cuttlebone as reinforcing filler for natural rubber. Eur Polym J 44:4157-4164

11. Cadman J, Zhou S, Chen Y, Li Q (2012) Cuttlebone: characterisation, application and development of biomimetic materials. J Bionic Eng 9:367-376

12. Tacon AGJ (1982) Utilisation of chick hatchery waste: the nutritional characteristics of day-old chicks and egg shells. Agric Wastes 4:335-343

13. Pettinato M, Chakraborty S, Arafat HA, Calabro V (2015) Eggshell: a green adsorbent for heavy metal removal in an MBR system. Ecotoxicol Environ Safe 121:57-62

14. Park HJ, Jeong SW, Yang JK, Kim BG, Lee SM (2007) Removal of heavy metals using waste eggshell. J Environ Sci 19:1436-1441

15. Witoon $\mathrm{T}$ (2011) Characterization of calcium oxide derived from waste eggshell and its application as $\mathrm{CO}_{2}$ sorbent. Ceram Int 37:3291-3298

16. Mohammadi M, Lahijani P, Mohamed AR (2014) Refractory dopant-incorporated $\mathrm{CaO}$ from waste eggshell as sustainable sorbent for $\mathrm{CO}_{2}$ capture: experimental and kinetic studies. Chem Eng J 243:455-464
17. Lin Z, Zhang Z, Mai K (2012) Preparation and properties of eggshell/ $\beta$-polypropylene bio-composites. J Appl Polym Sci 125:61-66

18. Supri AG, Ismail H, Shuhadah S (2010) Effect of polyethylenegrafted maleic anhydride (PE-g-MAH) on properties of low density polyethylene/eggshell powder (LDPE/ESP) composites. Polym Plast Technol Eng 49:347-353

19. Sutapun W, Pakdeechote P, Suppakarn N, Ruksakulpiwat Y (2013) Application of calcined eggshell powder as functional filler for high density polyethylene. Polym Plast Technol Eng 52:1025-1033

20. Katz SH, Weaver WW (2003) Encyclopedia of food and culture. Scribner, New York

21. Zhou J, Wang S, Nie F, Feng L, Zhu G, Jiang L (2011) Elaborate architecture of the hierarchical hen's eggshell. Nano Res 4:171-179

22. Vahabi H, Gholami F, Karaseva V, Laoutid F, Mangin R, Sonnier R, Saeb MR (2017) Novel nanocomposites based on poly (ethylene-co-vinyl acetate) for coating applications: the complementary actions of hydroxyapatite, MWCNTs and ammonium polyphosphate on flame retardancy. Prog Org Coat 113:207-217

23. Rastin H, Saeb MR, Nonahal M, Shabanian M, Vahabi H, Formela K, Gabrion X, Seidi F, Zarrintaj P, Sari MG (2017) Transparent nanocomposite coatings based on epoxy and layered double hydroxide: nonisothermal cure kinetics and viscoelastic behavior assessments. Prog Org Coat 113:126-135

24. Hafshejani TM, Zamanian A, Venugopal JR, Rezvani Z, Sefat F, Saeb MR, Vahabi H, Zarrintaj P, Mozafari M (2017) Antibacterial glass-ionomer cement restorative materials: a critical review on the current status of extended release formulations. J Control Release 262:317-328

25. Eshwaran SB, Basu D, Kutlu B, Leuteritz A, Wagenknecht U, Stöckelhuber KW, Naskar K, Das A, Heinrich G (2014) Stearate modified zinc-aluminum layered double hydroxides and acrylonitrile butadiene rubber nanocomposites. Polym Plast Technol Eng 53:65-73

26. Eshwaran SB, Basu D, Vaikuntam SR, Kutlu B, Wiessner S, Das A, Naskar K, Heinrich G (2015) Exploring the role of stearic acid in modified zinc aluminum layered double hydroxides and their acrylonitrile butadiene rubber nanocomposites. J Appl Polym Sci 132:41539

27. Raman VS, Rooj S, Das A, Stöckelhuber KW, Simon F, Nando GB, Heinrich G (2013) Reinforcement of solution styrene butadiene rubber by silane functionalized halloysite nanotubes. J Macromol Sci A 50:1091-1106

28. Collazo-Bigliardi S, Ortega-Toro R, Chiralt A (2018) Chapter 4: properties of micro-and nano-reinforced biopolymers for food applications, in book: polymers for food applications. Springer, Berlin

29. Saeb MR, Ghaffari M, Rastin H, Khonakdar HA, Simon F, Najafi F, Goodarzi V, Puglia D, Asl FH, Formela K (2017) Biowaste chicken eggshell powder as a potential cure modifier for epoxy/ anhydride systems: competitiveness with terpolymer-modified calcium carbonate at low loading levels. RSC Adv 7:2218-2230

30. Saeb MR, Rastin H, Nonahal M, Paran SMR, Khonakdar HA, Puglia D (2018) Cure kinetics of epoxy/chicken eggshell biowaste composites: isothermal calorimetric and chemorheological analyses. Prog Org Coat 114:208-215

31. Shi X, Rosa R, Lazzeri A (2010) On the coating of precipitated calcium carbonate with stearic acid in aqueous medium. Langmuir 26:8474-8482

32. Ghabeer T, Dweiri R, Al-Khateeb S (2013) Thermal and mechanical characterization of polypropylene/eggshell biocomposites. J Reinf Plast Comp 32:402-409 
33. Kumar R, Dhaliwal JS, Kapur GS (2014) Mechanical properties of modified biofiller-polypropylene composites. Polym Compos 35:708-714

34. Intharapat P, Kongnoo A, Kateungngan K (2013) The potential of chicken eggshell waste as a bio-filler filled epoxidized natural rubber (ENR) composite and its properties. J Polym Environ 21:245-258

35. Dakhel HR (2008) Using eggshell as a filler in elastomeric compounds: effect of incubation period on its performance toward elastomers. e-Polymers 8(1):140

36. Domčeková $S$, Ondrušová $D$, Mičicová Z, Pajtášová M, Moravčík R, Buňová L (2016) Effect of modified alternative filler on the properties of rubber compound. Procedia Eng 136:245-250

37. Jahromi AE, Jahromi HRE, Hemmati F, Saeb MR, Goodarzi V, Formela K (2016) Morphology and mechanical properties of polyamide/clay nanocomposites toughened with NBR/NBR-gGMA: a comparative study. Compos Part B 90:478-484

38. Toro P, Quijada R, Yazdani-Pedram M, Arias JL (2007) Eggshell, a new bio-filler for polypropylene composites. Mater Lett 61:4347-4350

39. Guth E (1945) Theory of filler reinforcement. J Appl Phys 16:20-25

40. Guth E, Gold O (1938) On the hydrodynamical theory of the viscosity of suspensions. Phys Rev 53:2-15

Publisher's Note Springer Nature remains neutral with regard to jurisdictional claims in published maps and institutional affiliations. 